\title{
Haemodynamic responses to exercise in patients with COPD
}

\author{
Janne Mykland Hilde*, Ingunn Skjørten\#, Viggo Hansteen*, Morten Nissen Melsom ", \\ Jonny Hisdal ${ }^{+}$, Sjur Humerfelt ${ }^{\#}$ and Kjetil Steine ${ }^{\S}$
}

ABSTRACT: The present study aimed to explore the prevalence of pre-capillary pulmonary hypertension $(\mathrm{PH})$ and characterise haemodynamic vascular responses to physical exercise in chronic obstructive pulmonary disease (COPD) outpatients, where left ventricular dysfunction and comorbidities were excluded.

98 patients with COPD underwent right heart catheterisation at rest and during supine exercise. Mean pulmonary artery pressure $(P$ pa $)$, pulmonary capillary wedge pressure $(P$ pcw $)$ and cardiac output (CO) were measured at rest and during exercise. Exercise-induced increase in mean $P$ pa was interpreted relative to increase in blood flow, mean $P$ pa/CO, workload $(W)$ and mean $P$ pa/W. Pulmonary vascular resistance (PVR) and pulmonary artery compliance (PAC) were calculated. $\mathrm{PH}$ at rest was defined as mean $P$ pa at rest $\geqslant 25 \mathrm{mmHg}$ and $P$ pcw at rest $<15 \mathrm{mmHg}$.

Prevalence of $\mathrm{PH}$ was $5 \%, 27 \%$ and $53 \%$ in Global Initiative for Chronic Obstructive Lung Disease stages II, III and IV, respectively. The absolute exercise-induced rise in mean Ppa did not differ between subjects with and without PH. Patients without PH showed similar abnormal haemodynamic responses to exercise as the PH group, with increased PVR, reduced PAC and steeper slopes for mean $\mathrm{Ppa} / \mathrm{CO}$ and mean $\mathrm{Ppa} / W$.

Exercise revealed abnormal physiological haemodynamic responses in the majority of the COPD patients. The future definition of PH on exercise in COPD should rely on the slope of mean $P$ pa related to cardiac output and workload rather than the absolute values of mean $P$ pa.

KEYWORDS: Pre-capillary, prevalence, pulmonary circulation, right heart catheterisation

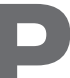

ulmonary hypertension $(\mathrm{PH})$ is a serious complication of chronic obstructive pulmonary disease (COPD). An increase in mean pulmonary artery pressure $(P$ pa $)$ at rest of $10 \mathrm{mmHg}$ is associated with a more than fourfold increase in mortality [1]. The actual prevalence of $\mathrm{PH}$ in COPD classified according to the Global Initiative for Chronic Obstructive Lung Disease (GOLD) is not well known [2].

Increased pulmonary artery stiffness is demonstrated early in the course of $\mathrm{PH}$, even in patients where PH is detectable only during exercise [3]. The resistance and elasticity of the pulmonary artery play an important role in facilitating the transition from right ventricular pulsatile flow to nearly steady state flow at the capillary level. There is, however, little knowledge of how the pulmonary haemodynamics, measured by right heart catheterisation (RHC), are affected during exercise in stable COPD patients.

Accordingly, the present study aimed to explore the prevalence of pre-capillary $\mathrm{PH}$ in a cohort of stable COPD patients, where left ventricular (LV) disease and comorbidities were systematically excluded. Furthermore, and based on the fact that alternation of the elastic properties of pulmonary artery is observed even in patients without established $\mathrm{PH}$, we hypothesised that abnormal haemodynamic vascular responses to exercise are also present in COPD patients without $\mathrm{PH}$.

\section{METHODS}

\section{Study population}

The present cross-sectional study was performed at Oslo University Hospital, Oslo, Norway, between 2006 and 2010. 98 consecutive COPD patients were prospectively enrolled from our pulmonary outpatient clinic. Prior to inclusion all the participants were assessed by one of three pulmonary physicians (I. Skjørten, M.N. Melsom or S. Humerfelt) and classified by severity of airway obstruction according to GOLD. COPD medical therapy was standardised according to the GOLD statement [2]. None of the subjects had

For editorial comments see page 1002.

AFFILIATIONS

*Dept of Cardiology, Oslo University Hospital, Aker,

\#Dept of Pulmonary Medicine, Oslo University Hospital, Aker

'Dept of Pulmonary Medicine, Oslo University Hospital, Oslo,

${ }^{+}$Section of Vascular Investigations, Oslo University Hospital, Aker, and ${ }^{\S}$ Dept of Cardiology, Akershus University Hospital, Oslo, Norway.

CORRESPONDENCE

J.M. Hilde

Oslo University Hospital-Aker Trondheimsveien 235 0514 Oslo

Norway

E-mail: j.m.hilde@medisin.uio.no

Received:

May 312012

Accepted after revision:

July 252012

First published online:

Aug 162012 
noninvasive positive-pressure ventilation support. Long-term treatment with oxygen was administered in eight patients and ambulatory oxygen support in four patients. $15 \%$ of the patients had chronic respiratory failure and, of those, four had hypercapnic respiratory insufficiency. The study was approved by the Local Research Ethics Committee, and all subjects gave written, informed consent. The study complies with the Declaration of Helsinki.

\section{Inclusion and exclusion criteria}

Norwegian Caucasian subjects, aged 40-75 years, with spirometrically confirmed COPD in GOLD stages II-IV, all either current or former smokers, with a smoking history of at least 10 packyears, were included. They had to have been free of COPD exacerbations during the last 2 months prior to inclusion. All participants underwent pre-inclusion screening, including resting ECG and an exercise test on cycle ergometer to screen for potential ischaemic heart disease. In addition, all subjects were screened by echocardiography at rest and during exercise, and moderate or severe tricuspid regurgitation jets were not observed. Patients with the following: LV disease, treated arterial hypertension with blood pressure $>160 / 90 \mathrm{mmHg}$, arrhythmias, intracardiac shunts, sleep apnoea syndrome, previous pulmonary embolism, other chronic pulmonary disease (pulmonary fibrosis or combined fibrosis/emphysema), malignancy, metabolic conditions (except metabolically stable diabetes), hyperthyroidism, systemic inflammatory diseases or renal failure with estimated glomerular filtration rate $<60 \mathrm{~mL} \cdot \mathrm{min}^{-1}$, were excluded. Patients using $\beta$-blockers, warfarin or clopidogrel or who could not perform bicycle-exercise testing or the 6-min walk test for any reason, were also excluded.

\section{Physical and pulmonary function testing}

Standardised 6-min walk distance (6MWD) without supplemental oxygen was obtained. Forced expiratory volume in $1 \mathrm{~s}$ (FEV1) and forced vital capacity (FVC) were determined by spirometry in accordance with international guidelines [4]. FEV1 and FVC predicted values were calculated [5]. GOLD classification was performed according to their best spirometric values and arterial oxygen tension $\left(\mathrm{PaO}_{2}\right)$ and arterial carbon dioxide tension $\left(\mathrm{PaCO}_{2}\right)$ on the test day after administration of their regular COPD medication. $\mathrm{PaO}_{2}$ and $\mathrm{PaCO}_{2}$ were obtained from the radial artery at rest and at maximal exercise breathing room air. Static lung volumes and diffusing capacity of the lung for carbon monoxide were measured $[4,6]$. Patients performed a standardised incremental maximal exercise test (the cardiopulmonary exercise test (CPET)), which involved 4 min of unloaded pedalling and 4 min of pedalling with $25 \mathrm{~W}$ workload $(W)$, followed by a progressive increase of $10 \mathrm{~W}$ every 2 min until exhaustion. The ratio of cardiac output (CO) to oxygen uptake $\left(V^{\prime} \mathrm{O}_{2}\right)$ was calculated as the change in $\mathrm{CO}$ from rest to exercise divided by the change in $V^{\prime} \mathrm{O}_{2}$. All patients underwent high-resolution computed tomography (HRCT) to evaluate the presence of emphysema. Pulmonary function measurements, HRCT and CPET were obtained within 1 day of the haemodynamic measurements.

\section{RHC and haemodynamic measurements}

A balloon-tipped 7 F Swan-Ganz catheter was inserted into the antecubital or femoral vein and advanced into the pulmonary artery during short-time fluoroscopy (ArcoScope; Siemens,
Munich, Germany). In the supine position, the pressures were zeroed at the mid-axillary line at the right atrial level, and automatic calibration was performed prior to pressure measurements. $\mathrm{CO}$ was measured by the thermodilution technique, averaging three or five output determinations. One $\mathrm{CO}$ measurement was performed at maximum workload. Mean $P$ pa and pulmonary capillary wedge pressure $(P \mathrm{pcw})$ were measured at rest and during the last minute of each exercise level, and right atrial pressure (Pra) at rest and at peak exercise, while right ventricular pressures were measured only at rest. Pressures were measured during temporary breathhold at endexpiration and verified by flat respiration curve. Post-processing analyses were performed on pressure curves at end-expiration at rest and during exercise by manually corrected region of interest if necessary. Computer-generated algorithmic of mean pressures (mean $P$ pa, mean $P$ ra and mean $P$ pcw) were used, and were averaged over three to six cardiac cycles. The ECG was monitored continuously.

The following haemodynamic variables were used: transpulmonary gradient $(\mathrm{TPG})=$ mean $P$ pa $-P$ pcw ; pulse pressure $(\mathrm{PP})=$ systolic Ppa-diastolic Ppa $(\mathrm{mmHg})$; stroke volume $(\mathrm{SV})=(\mathrm{CO} /$ cardiac frequency $(f C)) \times 1000\left(\mathrm{~mL}^{\circ}\right.$ beat $\left.{ }^{-1}\right)$; pulmonary artery compliance $(\mathrm{PAC})=\mathrm{SV} / \mathrm{PP}\left(\mathrm{mL} \cdot \mathrm{mmHg}^{-1}\right)$; pulmonary vascular resistance $(\mathrm{PVR})=($ mean $P$ pa $-P$ pcw $) / C O($ Wood units $)$ and total pulmonary vascular resistance $(\mathrm{TPR})=$ mean $P$ pa $/ \mathrm{CO}($ Wood units). Exercise-induced increase in mean $P$ pa was interpreted relative to the increase in blood flow (mean $P$ pa/CO) and workload (mean $\mathrm{Ppa} / W$ ).

Dynamic supine leg exercise using a cycle ergometer (ERGOMED 840L; Siemens) was performed. A steady-state resting period was followed by a stepwise increment in workload, starting with a 4min period of unloaded exercise $(0 \mathrm{~W})$ at $60 \mathrm{rpm}$, followed by $20 \mathrm{~W}$ for $4 \mathrm{~min}$, and then a $10-\mathrm{W}$ increment every 2 min until exhaustion while breathing room air.

As unloaded exercise at $0 \mathrm{~W}$ results in energy expenditure and augmentation in $V^{\prime} \mathrm{O}_{2}$ and $\mathrm{CO}$ with increase in mean $P$ pa, this "internal work" was added to the performed external work [7]. A correction factor was thus applied in all 98 participants, based on the known relationship between the increment in $V^{\prime} \mathrm{O}_{2}$ and workload during incremental exercise $\left(10 \mathrm{~mL} \cdot \mathrm{W}^{-1}\right)[8,9]$. Thus, $V^{\prime} \mathrm{O}_{2}$ was calculated for the workload of $0 \mathrm{~W}$. The increment in $V^{\prime} \mathrm{O}_{2}\left(\mathrm{~mL} \cdot \mathrm{min}^{-1}\right)$ from rest to $0 \mathrm{~W}$ was then used to calculate the "internal workload" and added to their external work during exercise, denoted as corrected workload [7]. The baseline and exercise pressure signals, respiration curves and the ECGs were digitally recorded using a Mac-Lab application (GE Healthcare Medical Systems, Milwaukee, WI, USA).

\section{Definition of haemodynamic groups}

Patients were divided into the following two main groups according to resting pressures: 1) non- $\mathrm{PH}$, where mean $P$ pa was $<25 \mathrm{mmHg}$ and $P$ pcw was $\leqslant 15 \mathrm{mmHg}$; and 2) established pre-capillary $\mathrm{PH}$, where mean $P$ pa was $\geqslant 25 \mathrm{mmHg}$ and $P$ pcw was $\leqslant 15 \mathrm{mmHg}$ [10]. A PVR $>1.5$ Wood units at rest (corresponding to upper limit of the $95 \%$ confidence interval for healthy controls (mean $\pm 1.96 \mathrm{SD})$ ) was considered elevated in subjects aged $>50$ years [11]. 


\section{Statistical analysis}

The results of continuous variables are reported as mean \pm SD or mean \pm SEM. Categorical variables are expressed as frequencies or percentages. An independent t-test was used to compare the mean of two different groups, and a paired t-test used to compare mean differences between rest and exercise within the same group. A p-value $<0.05$ were considered statistically significant. For categorical variables, the Chi-squared test was used. Non-normally distributed data were log-transformed (N-terminal pro-brain natriureteric peptide (NT-proBNP)). Multivariate linear regression was used to determine whether higher resting mean $P$ pa and exercise PVR were associated with a shorter 6MWD, independent of potential confounders. The statistical analyses were performed using SPSS version 15 (SPSS Inc., Chicago, IL, USA) and SigmaPlot version 12.0 (Systat Software, Inc., London, UK).

\section{RESULTS}

\section{Demographic characteristics}

Demographic and pulmonary function characteristics are listed in table $1.33(34 \%)$ patients of the study population were treated for essential systemic hypertension. No differences in systolic or diastolic blood pressure were observed between those treated for and those without hypertension. Emphysema was diagnosed in all except three patients. These three did not differ from the rest with respect to haemodynamic data; however, the group was too small to make any conclusion. Respiratory failure (defined as $\mathrm{PaO}_{2}<8 \mathrm{kPa}$ ) was observed in eight patients, all in GOLD stage IV and on chronic oxygen treatment. Four patients were on ambulatory oxygen, two each in GOLD stage III and IV, respectively. The oxygentreated group comprised seven patients with $\mathrm{PH}$ (mean $P$ pa at rest $30 \pm 5$, range $25-40 \mathrm{mmHg}$ and $\mathrm{PaO}_{2} 7.5 \pm 1.8 \mathrm{kPa}$ ), and five without (mean $P$ pa at rest $22 \pm 1$, range $20-23 \mathrm{mmHg}$ and $\mathrm{PaO}_{2}$ $7.9 \pm 0.7 \mathrm{kPa})$.

\section{Haemodynamic profile at rest}

The haemodynamic variables and arterial blood gas profile in the two groups are summarised in table 2. The prevalence of $\mathrm{PH}$ was $27 \%$ (26 patients) and of non-PH was $73 \%$ (72 patients). Distribution of mean $P$ pa related to GOLD stages is shown in figure 1. PVR was elevated at rest in all patients with $\mathrm{PH}$ and in $50(69 \%)$ patients in the non-PH group. PAC was significantly reduced in the PH group $(\mathrm{p}<0.01)$ compared with the non-PH group (table 2). Right ventricular function was normal at rest in both groups according to CO and Pra (table 2), and none had elevated Ppcw.

\section{Haemodynamic profile at peak exercise}

The relationship between $\mathrm{CO}$ and workload is illustrated in figure 2. A CO increase of $68 \%$ and $100 \%$ in the $\mathrm{PH}$ and non$\mathrm{PH}$ groups was associated with a $66 \%$ and $105 \%$ increase in mean $P$ pa, respectively. There was no significant difference in the absolute mean $P$ pa increase in response to maximal exercise between the groups (fig. 3).

PVR increased significantly by $11 \%$ in the $\mathrm{PH}$ group during exercise $(p=0.04)$. In the non-PH group, a nonsignificant increase of $5 \%$ in PVR was observed $(p=0.08)$. However, considering percentage change in PVR from rest to exercise, adjusted for changes in $\mathrm{CO}$, a similar increase in PVR of $6.3 \%$ in non-PH group as in $\mathrm{PH}$ group $(6.9 \%)$ was observed $(\mathrm{p}=0.9)$.

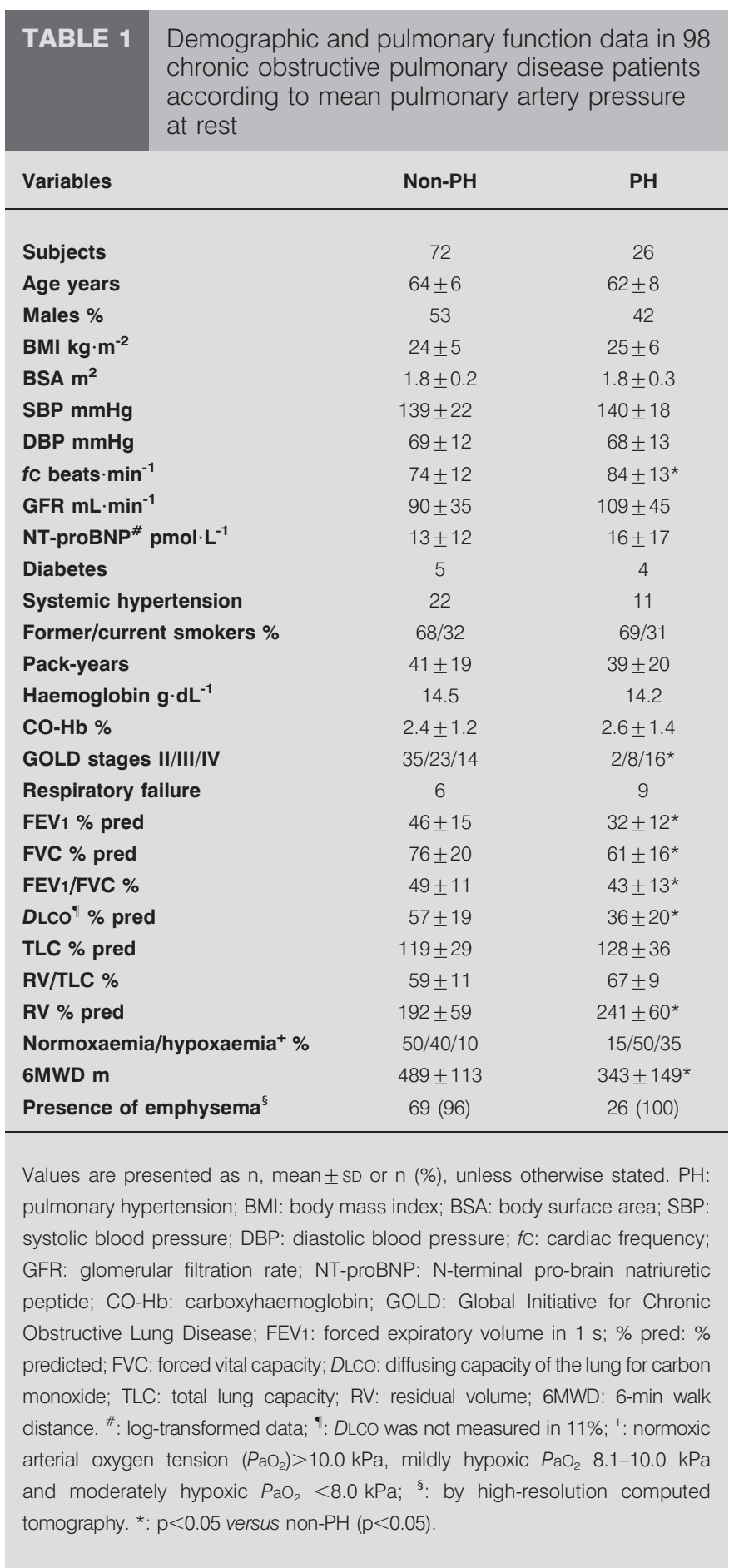

For both groups, TPR was significantly increased from rest to exercise $(\mathrm{p}<0.01$ for both); however, there were no differences in TPR increases between the groups ( $p>0.8)$ (fig. 4).

The increase in PP from rest to exercise exceeded the increase in SV. Hence, PAC decreased in response to exercise by $47 \%$ and $44 \%$ in $\mathrm{PH}$ and non-PH, respectively (table 3 ). However, the increase in PVR was accompanied by a relatively larger drop in PAC in the non- $\mathrm{PH}$ group compared with the $\mathrm{PH}$ group (PVR/PAC ratio $0.6 \pm 0.4$ versus $1.5 \pm 1.4$, respectively; 


\begin{tabular}{|c|c|c|c|c|}
\hline \multirow[t]{2}{*}{ Variable } & \multicolumn{2}{|c|}{ Non-PH } & \multicolumn{2}{|c|}{ PH } \\
\hline & Rest & Exercise & Rest & Exercise \\
\hline Subjects $\mathrm{n}$ & \multicolumn{2}{|c|}{72} & \multicolumn{2}{|c|}{26} \\
\hline $\mathrm{dPpa} \mathrm{mmHg}$ & $9 \pm 4$ & $20 \pm 7$ & $17 \pm 6^{\#}$ & $28 \pm 7^{\circ}$ \\
\hline TPG mmHg & $10 \pm 3$ & $20 \pm 6$ & $18 \pm 6^{\#}$ & $31 \pm 7^{\circ}$ \\
\hline Ppcw mmHg & $9 \pm 3$ & $17 \pm 4$ & $11 \pm 3^{\#}$ & $17 \pm 4$ \\
\hline Pra mmHg & $5 \pm 3$ & $9 \pm 3$ & $7 \pm 3^{\#}$ & $11 \pm 3$ \\
\hline PP $\mathrm{mmHg}$ & $18 \pm 5$ & $35 \pm 9$ & $24 \pm 9^{\#}$ & $39 \pm 9$ \\
\hline edPRV $\mathrm{mmHg}$ & $7 \pm 4$ & & $10 \pm 4^{\#}$ & \\
\hline fc beats $\min ^{-1}$ & $74 \pm 12$ & $108 \pm 13$ & $84 \pm 13^{\#}$ & $110 \pm 15$ \\
\hline MPfC \% & & $69 \pm 9$ & & $69 \pm 10$ \\
\hline$W c \mathrm{~W}$ & & $74 \pm 25$ & & $50 \pm 20^{\circ}$ \\
\hline $\mathrm{PaO}_{2} \mathrm{kPa}$ & $9.8 \pm 1.2$ & $9.4 \pm 1.6$ & $8.2 \pm 1.6^{\#}$ & $7.3 \pm 1.9^{\circ}$ \\
\hline $\mathrm{PaCO}_{2} \mathbf{k P a}$ & $5.3 \pm 0.6$ & $5.6 \pm 0.8$ & $5.7 \pm 0.8^{\#}$ & $6.2 \pm 1.1^{\circ}$ \\
\hline $\mathrm{SaO}_{2} \%$ & $96 \pm 2$ & $94 \pm 4$ & $92 \pm 5^{\#}$ & $85 \pm 9^{\circ}$ \\
\hline $\mathrm{CO} / \mathrm{N}^{\prime} \mathrm{O}_{2}$ & & $6.2 \pm 4.1$ & & $6.3 \pm 2.7$ \\
\hline Maximum Borg 10 dyspnoea score & & $9.3 \pm 1.4$ & & $9.2 \pm 1.7$ \\
\hline$f R$ breaths $\cdot \mathrm{min}^{-1}$ & $20 \pm 4$ & $35 \pm 7$ & $23 \pm 6^{\#}$ & $33 \pm 8$ \\
\hline Respiratory quotient & & $1.0 \pm 0.1$ & & $0.9 \pm 0.1$ \\
\hline
\end{tabular}

Data are presented as mean \pm SD, unless otherwise indicated. Ppa: pulmonary artery pressure; sPpa: systolic $P$ pa; $d P$ pa: diastolic $P$ pa; TPG: transpulmonary pressure gradient; Ppcw: pulmonary capillary wedge pressure; Pra: right atrial pressure; PP; pulse pressure; TPR: total pulmonary vascular resistance; PVR: pulmonary vascular resistance; PAC: pulmonary arterial compliance; CO: cardiac output; edPRV: right ventricle end-diastolic pressure; fC: cardiac frequency; MPfc: maximum predicted fc; Wc: corrected workload; $\mathrm{PaO}_{2}$ : arterial oxygen tension; $\mathrm{PaCO}_{2}$ : arterial carbon dioxide tension; $\mathrm{SaO}_{2}$ : arterial oxygen saturation; $V^{\prime} \mathrm{O}_{2}$ : oxygen uptake; fR: respiratory frequency; $V^{\prime}$ Emax: maximum minute ventilation; MVV: maximal voluntary ventilation. ${ }^{\#}: p<0.05$, significantly different from non-PH for resting values; ${ }^{"}: p<0.05$, significantly different from non$\mathrm{PH}$ for exercise values. For all right heart catheterisation variables, except PVR in the non-PH group, there was a significant difference between rest and exercise values for haemodynamic variables. Workload obtained in cardiopulmonary exercise testing was similar to workload from right heart catheterisation.

$\mathrm{p}<0.01)$. Adjusted for workload, Ppcw showed a similar increase in response to exercise in both groups. 14 patients (four and 10 in the $\mathrm{PH}$ and non-PH groups, respectively) showed a more pronounced $P$ pcw response to exercise than the rest (average maximal $P$ pcw $23 \pm 2$, range $21-26 \mathrm{mmHg}$ ). In table 3 , the slopes related to workload and $\mathrm{CO}$ for haemodynamic parameters are summarised. Figure 5 illustrates how all 98 change $(\Delta)$ in mean $P$ pa $/ \Delta C O$ slopes are related to mean $P$ pa at rest in non-PH and $\mathrm{PH}$ groups. There was only a weak correlation between mean $P$ pa at rest and $\Delta$ mean $P$ pa $/ \Delta C O$ $(\mathrm{r}=0.2 ; \mathrm{p}<0.05)$.

\section{Contribution of Ppcw and TPG to increase in mean Ppa by exercise}

The $\Delta P$ pcw $/ \Delta$ TPG ratio in the PH group was 0.5 , and 0.8 in the non-PH group, reflecting a larger contribution of TPG than $P$ pcw to mean $P$ pa by exercise. The relative changes in mean
Ppa, Ppcw, TPG, PVR and TPR from rest to exercise are shown in figure 4 , and the slopes are presented in table 3.

\section{Changes in blood gases by exercise and their relationship with haemodynamics}

From rest to peak exercise a decline in relative arterial oxygen saturation $\left(\mathrm{SaO}_{2}\right)$ of $2 \pm 3$ and $8 \pm 7 \%$ was observed in non-PH and $\mathrm{PH}$ groups, respectively $(\mathrm{p}<0.01)$. The relative $\mathrm{SaO}_{2}$ decline was significantly lower for the non-PH group $(0.06 \pm 0.1 \%$ per $\mathrm{W})$ than for the PH group $(0.3 \pm 0.4 \%$ per $\mathrm{W} ; \mathrm{p}<0.01)$, which showed a fivefold larger decline in $\mathrm{SaO}_{2}$ when related to maximum workload. During peak exercise, mean $P$ pa was negatively correlated to maximal $\mathrm{PaO}_{2}(\mathrm{r}=-0.5 ; \mathrm{p}<0.01)$ in the entire cohort. The non-PH group, however, showed only a weak negative correlation between mean maximal $P$ pa and maximal $\mathrm{PaO}_{2}$ $(\mathrm{r}=-0.4 ; \mathrm{p}<0.01)$, while the $\mathrm{PH}$ group did not correlate at all $\left(\mathrm{r}=0.2\right.$; nonsignificant). PVR rest did not correlate with $\mathrm{PaO}_{2}$ at 


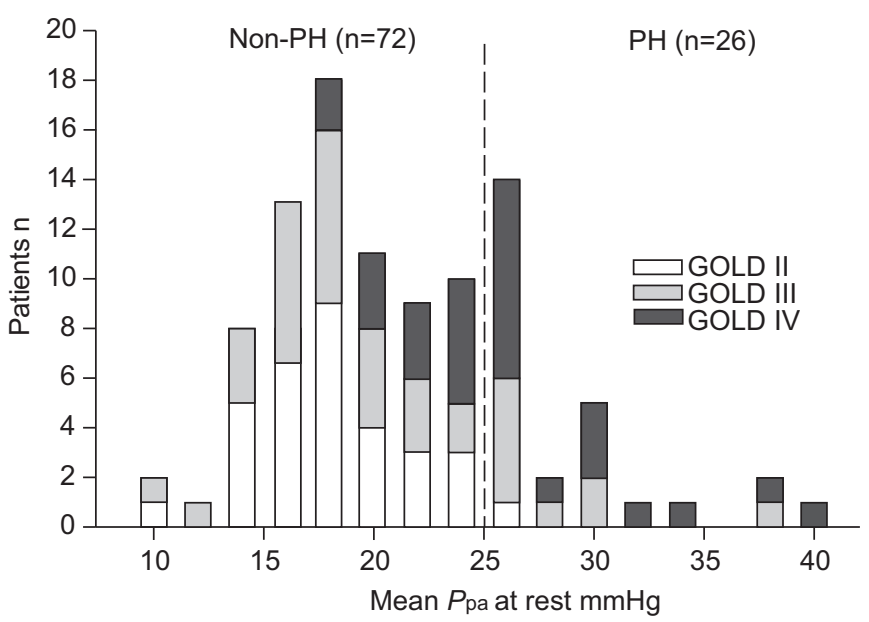

FIGURE 1. Distribution of mean pulmonary artery pressure $(P$ pa) in an outpatient cohort of 98 chronic obstructive pulmonary disease (COPD) patients in GOLD (Gobal Initiative for Chronic Lung Disease) severity stages II, III and IV. 72 patients had normal pulmonary artery pressure (nonpulmonary hypertension (non-PH)) and 26 had PH. The number of patients diagnosed with $\mathrm{PH}$ according to GOLD stage II, III and IV were 2, 8 and 16, respectively. The dotted line represents the current guideline definition of $\mathrm{PH}$

rest in the non-PH group, while in the $\mathrm{PH}$ group, a strong negative correlation between PVR at rest and $\mathrm{PaO}_{2}$ at rest $(\mathrm{r}=-0.6 ; \mathrm{p}<0.01)$ was observed. PVR during peak load did correlate with maximal $\mathrm{PaO}_{2}$ in both groups $(\mathrm{r}=-0.5 ; \mathrm{p}<0.01)$.

\section{Functional outcomes}

Adjusted for age, sex, height, weight, FEV1 and $P$ pcw, mean $P$ pa at rest was negatively associated with $6 \mathrm{MWD}(\mathrm{r}=-0.55 ; \mathrm{p}<0.01)$. A 9.5-m decline in 6MWD for every $1-\mathrm{mmHg}$ increase in mean Ppa $(95 \%$ CI $-14.3--4.5 \mathrm{~m}$; p <0.01) was observed. Adjusted for the same confounding variables in addition to $\mathrm{SaO}_{2}$ measured by pulse oximetry, PVR was inversely related to 6MWD $(r=-0.6$; $\mathrm{p}<0.01)$. This multivariable linear regression model with $6 \mathrm{MWD}$ as dependent variable showed that for every Wood unit increase in PVR at peak exercise, the 6MWD dropped by $29.5 \mathrm{~m}(95 \% \mathrm{CI}$ -48.9- -10.1 m; $\mathrm{p}<0.01)$. Furthermore, maximal workload was strongly correlated to PVR and PAC at peak workload $(r=-0.7$ and $\mathrm{r}=0.5$, respectively; $\mathrm{p}<0.01$ for both).

30 COPD patients showed a $\Delta$ mean $P$ pa $/ \Delta \mathrm{CO}<3 \mathrm{mmHg} \cdot \mathrm{L}^{-1}$. $\min ^{-1}\left(2.1 \pm 0.6\right.$, range $\left.1.05-2.92 \mathrm{mmHg} \cdot \mathrm{L}^{-1} \cdot \mathrm{min}^{-1}\right)$, representing "true circulatory normal" (fig. 6).

\section{DISCUSSION}

In the present cohort of COPD patients, recruited from an outpatient population where LV dysfunction, comorbidities and exacerbations were thoroughly excluded, a prevalence of pre-capillary $\mathrm{PH}$ of $27 \%$ was found. The prevalence related to GOLD stage II, III and IV was 5\%, 27\% and 53\%, respectively. As expected, abnormal exercise-induced haemodynamic responses were observed in the $\mathrm{PH}$ group. However, similar and comparable haemodynamic responses to exercise were also demonstrated in non-PH subjects. Based on these results and previous findings in healthy subjects, we consider the responses to exercise in non-PH subjects as abnormal.

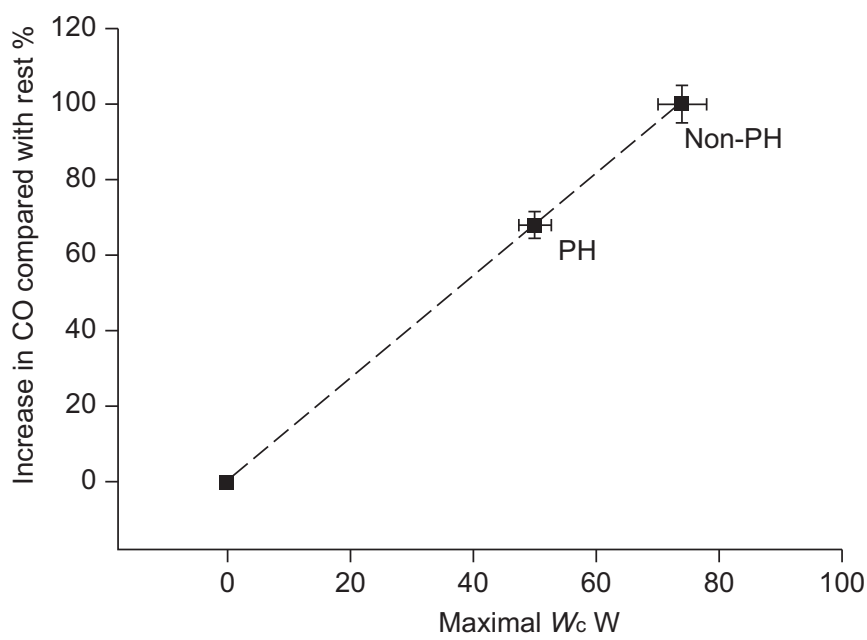

FIGURE 2. Relationship between the corrected workload (Wc) and percentage increase in cardiac output $(\mathrm{CO})$ in chronic obstructive pulmonary disease patients. Average increase in workload in the pulmonary hypertension (PH) group was 68\% of the increase in the non- $\mathrm{PH}$ group, corresponding to an increase in $\mathrm{CO}$ of $68 \%$ and $100 \%$ in the $\mathrm{PH}$ and non-PH group, respectively. Data are presented as mean \pm SEM

\section{Mean Ppa at rest}

The majority of prevalence data are based on patients with severe to very severe COPD disease, i.e. awaiting lung transplantation, where RHC is a part of routine clinical evaluation. Previous studies have reported prevalence of $\mathrm{PH}$ in COPD patients to vary between $30 \%$ and $90 \%$ [15-19]. The inconsistency in prevalence of $\mathrm{PH}$ associated with COPD is based mainly upon dissimilarities in definition of $\mathrm{PH}$, methods used to determine mean $P$ pa, the physiological characteristics of the underlying lung disease and patient population examined [20]. In the present study, great effort was made to ensure inclusion of COPD patients who were clinically stable and optimally treated and without evidence of LV dysfunction either at rest or during exercise. Our prospectively collected data showed a lower prevalence of pre-capillary $\mathrm{PH}$ than in the majority of previous studies. Only $27 \%$ of our patients met the current definition of $\mathrm{PH}$ (mean $\mathrm{Ppa} \geqslant 25 \mathrm{mmHg}$ ) [10]. This lower prevalence compared with published estimates of $\mathrm{PH}$ reflects the present study's more restrictive definition and, secondly, a very strict selection process to avoid including comorbidities (i.e. both post- and other pre-capillary diseases) that could contribute to a rise in mean $P$ pa. Using the previous definitions of $\mathrm{PH}$ (mean $\mathrm{Ppa}>20 \mathrm{mmHg}$ ), the prevalence of pre-capillary $\mathrm{PH}$ would have been $46 \%$ [19]. The average $18 \mathrm{mmHg}$ resting mean $\mathrm{Ppa}$ value in the non- $\mathrm{PH}$ group in the present study is higher than that reported for healthy subjects [13], but in accordance with the study in 1999 by KESSLER et al. [21] on stable outpatients with COPD.

\section{Mean Ppa response to increased $\mathrm{W}$ and $\mathrm{CO}$}

Workload and $\mathrm{CO}$ had a similar impact on the pressure increase of mean $P$ pa. The absolute increase in mean $P$ pa by exercise was also similar in those with and without $\mathrm{PH}$. However, there was a larger increase in mean $P$ pa in the $\mathrm{PH}$ compared with non-PH group, which was related to the 

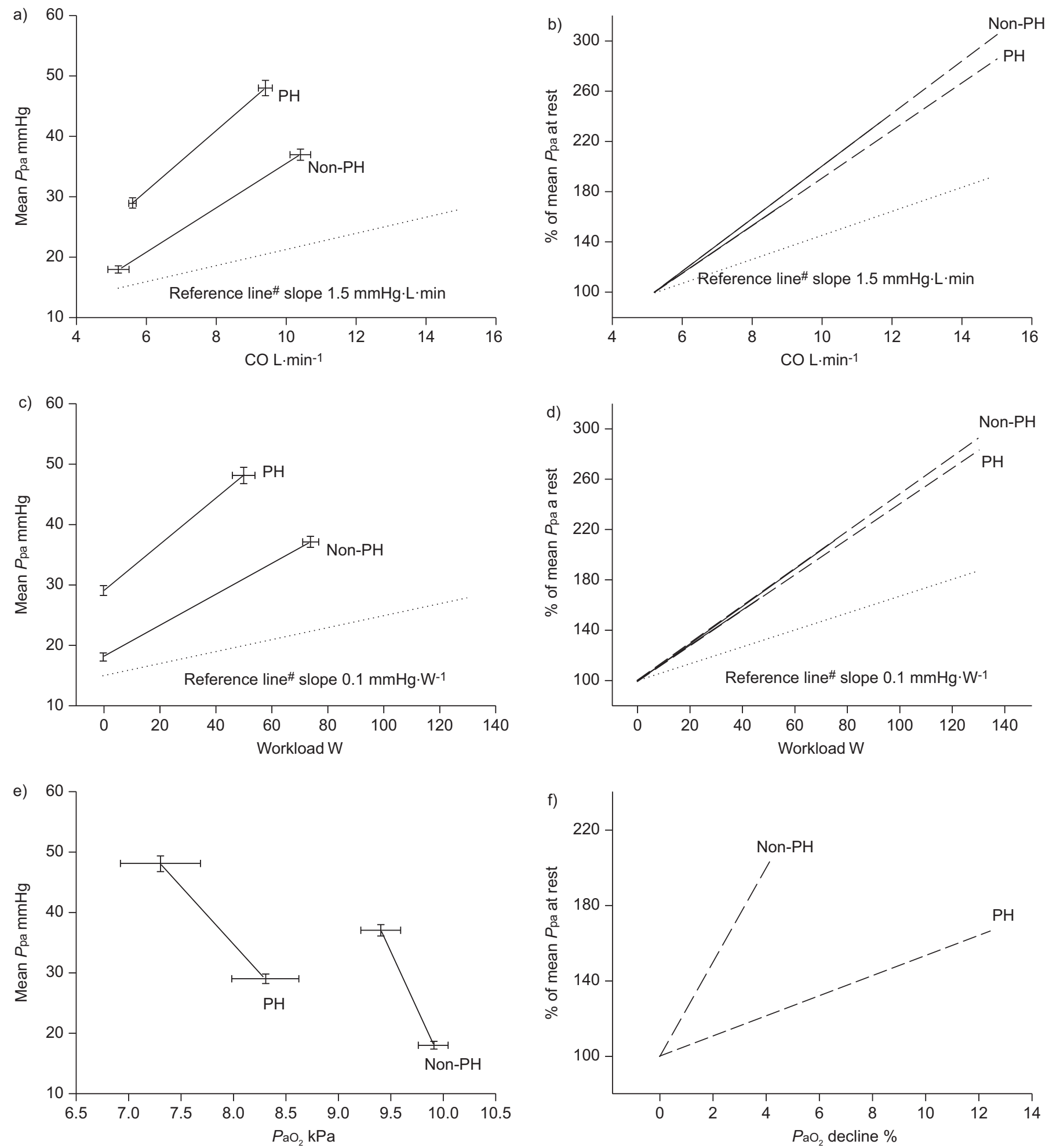

FIGURE 3. Measurements at rest and during maximal exercise in patients with chronic obstructive pulmonary disease categorised as pulmonary hypertension (PH) and non-PH are shown. a) Shows changes in mean pulmonary artery pressure ( $P$ pa) relative to changes in cardiac output (CO), c) shows changes in workload and e) shows changes in arterial oxygen tension $\left(\mathrm{PaO}_{2}\right) \cdot \mathrm{b}, \mathrm{d}$ and $\mathrm{f}$ ) illustrate the relative change in mean $\mathrm{Ppa}$ from rest (resting mean $\mathrm{Ppa}=100 \%$ ) to peak exercise (unbroken lines) in relation to the increase of $\mathrm{CO}$, workload and $\mathrm{PaO}_{2}$ decline in non- $\mathrm{PH}$ and $\mathrm{PH}$, respectively; the broken lines are extrapolations of the relative mean $P$ pa increase until $15 \mathrm{~L} \cdot \mathrm{min}^{-1}$ (CO) and $140 \mathrm{~W}$ (workload) in both groups. Despite of a relatively minor decline in $\mathrm{PaO}_{2}$ in the non- $\mathrm{PH}$ group, exaggerated responses in mean $\mathrm{Ppa}$ were observed. ${ }^{\#}$ : reference lines (dotted) are based on previously published mean values on healthy controls [7, 12]. 


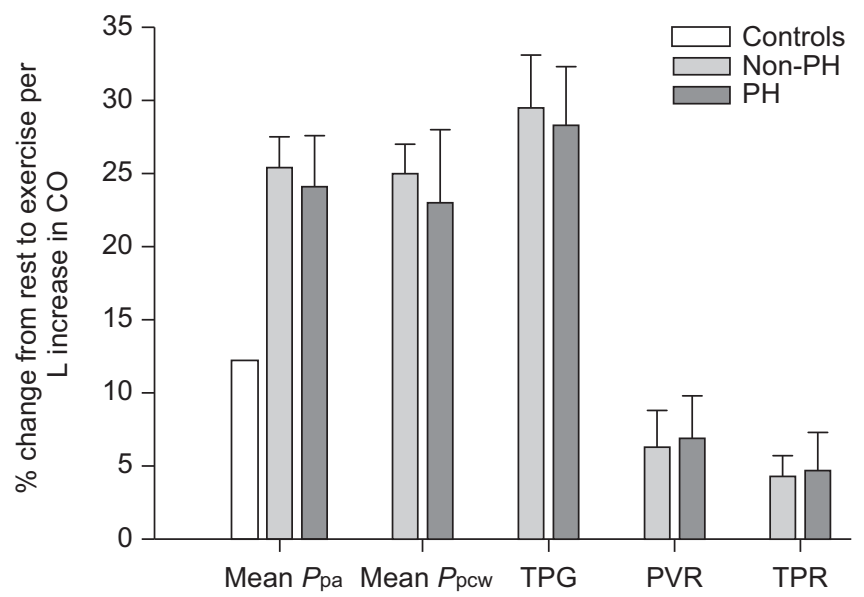

FIGURE 4. Percentage change from rest to peak exercise per litre change in cardiac output (CO) for five haemodynamic variables in pulmonary hypertension $(\mathrm{PH})$ and non- $\mathrm{PH}$; reference values are for historical controls of $>50$ years adapted from Kovacs and co-workers [11, 13]. Ppa: pulmonary artery pressure; Ppcw: pulmonary capillary wedge pressure; TPG: transpulmonary gradient; PVR: pulmonary vascular resistance; TPR: total pulmonary vascular resistance. Data are presented as mean \pm SEM.

increase in workload and CO. Thus, our results clearly support that exercise-induced rise in mean $P$ pa should be interpreted relative to increase in workload or increase in $\mathrm{CO}$, rather than by evaluating a single threshold or an absolute peak exercise value of mean $P$ pa, as highlighted by SAGGAR et al. [22]. In this context, we are in agreement with the decision of the Working Group on Diagnosis and Assessment of Pulmonary Arterial Hypertension that, in 2008, withdrew exercise mean $P$ pa $>30 \mathrm{mmHg}$ as a diagnostic criteria for $\mathrm{PH}$.

Comparable haemodynamic data in healthy controls are limited due to ethical reasons, but some data have been

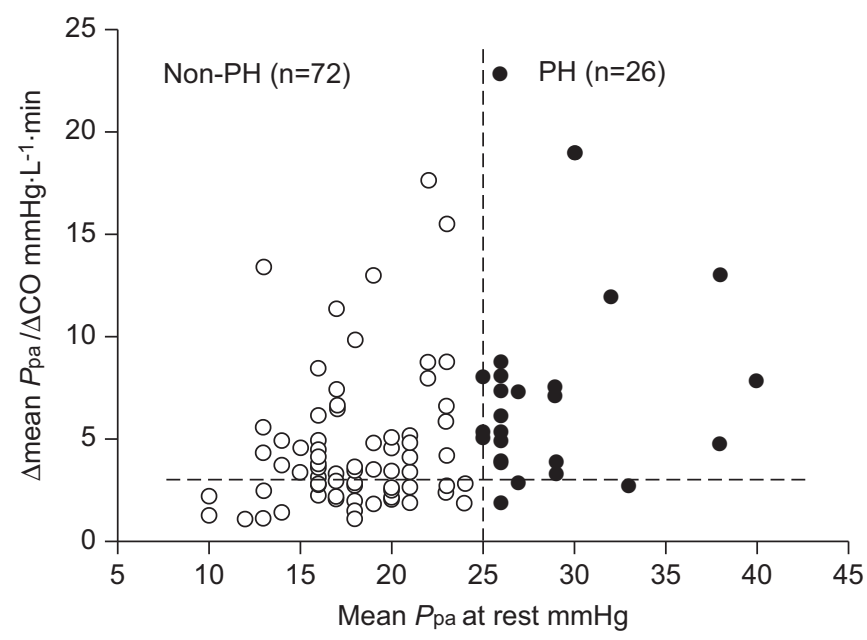

FIGURE 5. The relationship between change $(\Delta)$ in mean pulmonary artery pressure $(\mathrm{Ppa}) / \Delta$ in cardiac output (CO) slopes and mean $P$ pa at rest in 98 chronic obstructive pulmonary disease patients either with $(\mathrm{PH})$ or without pulmonary hypertension (non-PH). The vertical dotted line is the current cut-off value for $\mathrm{PH}$ and the horizontal dotted line represents the slope cut-off $\left(3 \mathrm{mmHg} \cdot \mathrm{L}^{-1} \cdot \mathrm{min}\right.$ as suggested by LEWIS [14]). 58\% of the patients in the non-PH group had $\Delta$ mean $P$ pal $\Delta$ CO slopes $>3 \mathrm{mmHg} \cdot \mathrm{L}^{-1} \cdot \mathrm{min}$.

reported, albeit with small numbers of subjects in all studies [7, $12,13]$. LEWIS et al. [7] reported a $\Delta$ mean $P$ pa $/ \Delta C O$ slope of $1.4 \mathrm{mmHg} \cdot \mathrm{L}^{-1} \cdot \min$ (age $60 \pm 12$ years), and in a slightly younger cohort (age $41 \pm 4.8$ years); DeGRE et al. [12] demonstrated $1.5 \mathrm{mmHg} \cdot \mathrm{L}^{-1}$. In a study by Kovacs et al. [13] on healthy controls aged $>50$ years, a $\Delta$ mean $\mathrm{Ppa} / \Delta \mathrm{CO}$ of $2.8 \mathrm{mmHg} \cdot \mathrm{L}^{-1} \cdot \mathrm{min}$ was demonstrated, and in a study of healthy older males (age $71 \pm 6$ years), GRANATH et al. [23] reported a slope of $2.5 \pm 0.8 \mathrm{mmHg} \cdot \mathrm{L}^{-1} \cdot \mathrm{min}$. In the present study, we have shown slopes of 7.2 and $4.6 \mathrm{mmHg} \cdot \mathrm{L}^{-1} \cdot \mathrm{min}$ in $\mathrm{PH}$ and non-PH groups, respectively. Compared with the

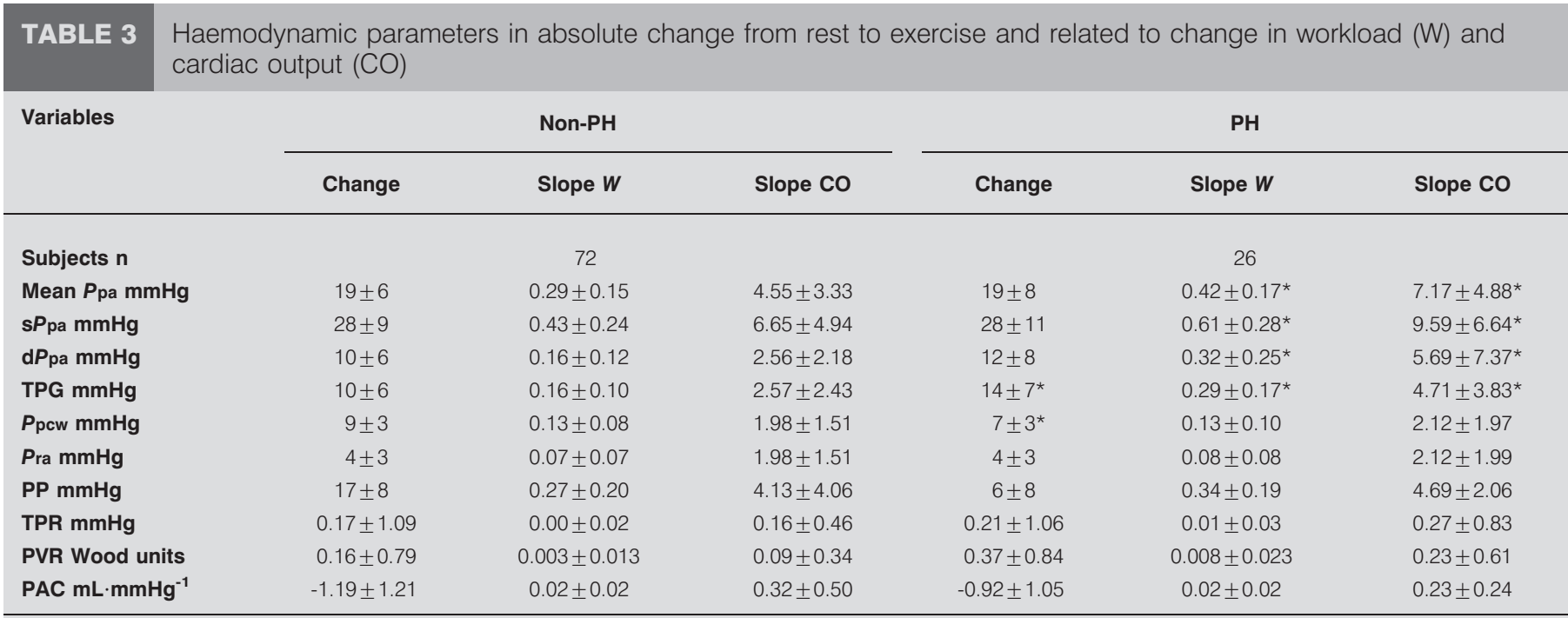

Data are presented as mean $\pm \mathrm{SD}$, unless otherwise stated. $\mathrm{PH}$ : pulmonary hypertension; $P$ pa: pulmonary artery pressure; $\mathrm{S} P$ pa: systolic pulmonary artery pressure; $\mathrm{dPpa}$ diastolic pulmonary artery pressure; TPG: transpulmonary pressure gradient; $P$ pcw: pulmonary capillary wedge pressure; Pra: right atrial pressure; TPR: total pulmonary resistance; PVR: pulmonary vascular resistance; PAC: pulmonary arterial compliance. *: $p<0.05$ versus non-PH. 

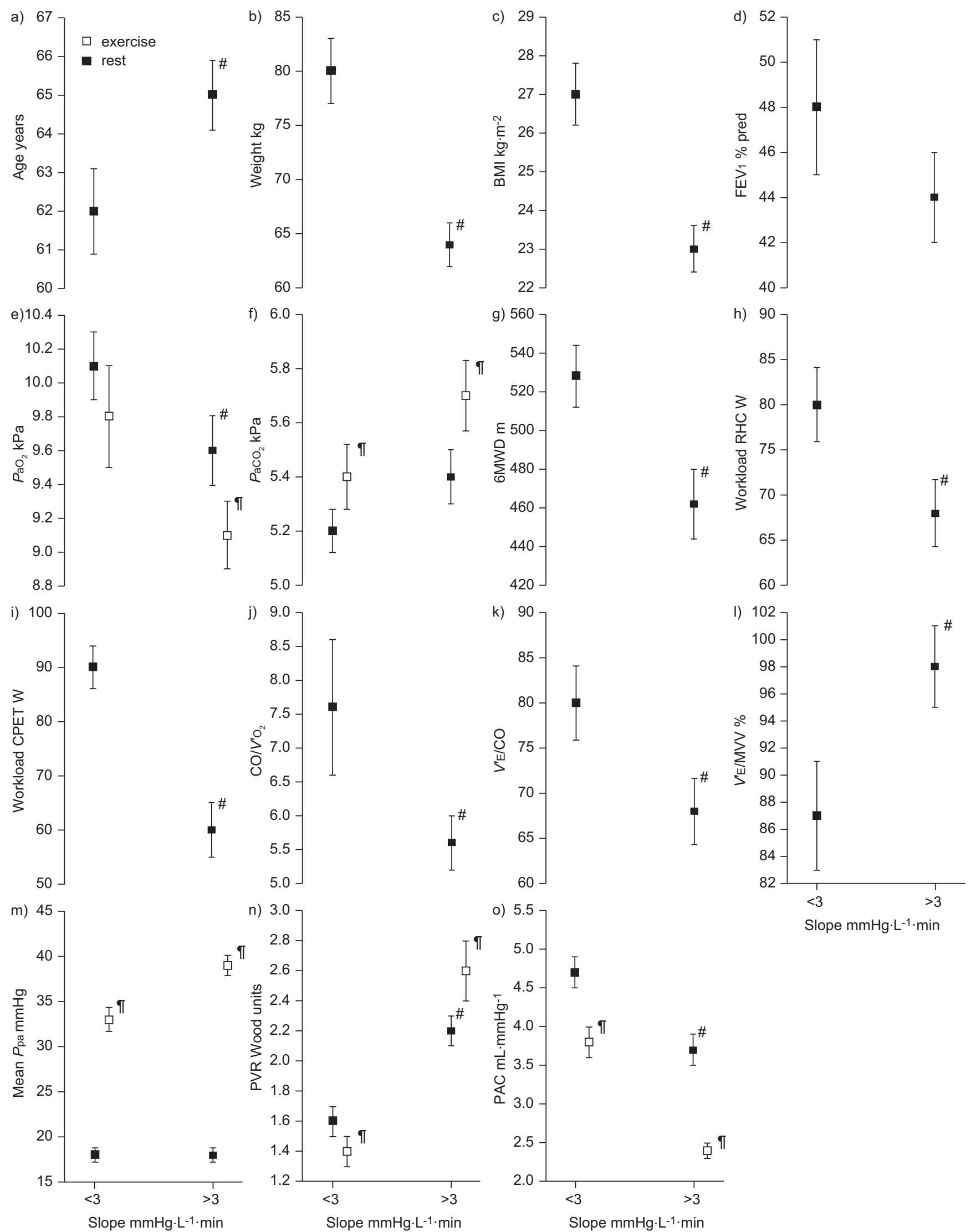

,

Slope $\mathrm{mmHg} \cdot \mathrm{L}^{-1} \cdot \mathrm{min}$

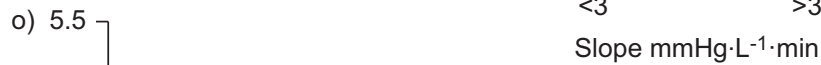

FIGURE 6. Figure caption can be found on the following page. 
FIGURE 6. Illustration of key differences and similarities of nonpulmonary hypertension (non- $\mathrm{PH})$ patients with change $(\Delta)$ in mean pulmonary artery pressure $(P$ pa) $/ \Delta$ in cardiac output (CO) slope $<3 \mathrm{mmHg} \cdot \mathrm{L}^{-1}(\mathrm{n}=30)$ and $>3 \mathrm{mmHg} \cdot \mathrm{L}^{-1}(\mathrm{n}=42)$. Those $<3 \mathrm{mmHg} \cdot \mathrm{L}^{-1}$ are considered to represent "true circulatory normal" and those $>3 \mathrm{mmHg} \cdot \mathrm{L}^{-1}$ to represent the exercise-induced $\mathrm{PH}$ population. $\mathrm{BMI}$ : body mass index; $\mathrm{FEV}_{1}$ : forced expiratory volume in $1 \mathrm{~s} ; \%$ pred: \% predicted; $P$ aO 2 : arterial oxygen tension; $\mathrm{PaCO}_{2}$ : arterial carbon dioxide tension; 6MWD: 6-min walk distance; $\mathrm{RHC}$ : right heart catheterisation; $\mathrm{CPET}$ : cardiopulmonary exercise test; $V^{\prime} \mathrm{O}_{2}$ : oxygen uptake; $V^{\prime} \mathrm{E}$ : minute ventilation; MVV: maximal voluntary ventilation; PVR: pulmonary vacular resistance; PAC: pulmonary artery compliance. Data are presented as mean \pm SEM. ${ }^{\#}$ : $\mathrm{p}<0.05$, significantly different from $<3 \mathrm{mmHg} \cdot \mathrm{L}^{-1} \mathrm{~min},{ }^{\top}: \mathrm{p}<0.05$, significantly different from rest to exercise. No significance difference between the groups with regard to presence of emphysema.

previous studies on healthy controls, our data indicate a pathological mean $P$ pa response to exercise also exists in a large proportion of the COPD patients without $\mathrm{PH}$ (fig. 5). A cut-off point for mean $P \mathrm{pa} / \mathrm{CO}$ of $>3 \mathrm{mmHg} \cdot \mathrm{L}^{-1} \cdot \mathrm{min}$, as proposed by LEWIS [14], should reinforce this notion. Moreover, in contrast to mean $P$ pa at rest, mean $P$ pa during exercise has been shown to be strongly related to pulmonary arterial wall thickness in COPD; the authors suggested that this reflects reduced distensability and recruitability of pulmonary vessels in COPD, and that the degree of remodelling could not be estimated by mean $P$ pa at rest [24]. Our study also confirmed a poor relationship between mean $P$ pa at rest and $\Delta$ mean $P$ pa $/ \Delta \mathrm{CO}$.

\section{Contribution of TPG and Ppcw to the exercise-induced increment in mean Ppa}

Previous haemodynamic studies in healthy subjects have demonstrated a greater contribution of $\Delta P \mathrm{pcw}$ compared with $\triangle T P G$ to exercise-induced increase in mean $P$ pa with a ratio of $\sim 2$ [25-27]. In our study, an inverse ratio for both non-PH and $\mathrm{PH}$ groups was observed, consistent with a larger contribution of $\triangle T P G$ to the increase in mean $P$ pa compared with $\Delta P \mathrm{pcw}$, reflecting pre-capillary pathology in the non-PH and $\mathrm{PH}$ groups. In both groups, this increase of $\triangle \mathrm{TPG}$ was related to pathological PVR response. In healthy subjects, PVR and also TPR are normally slightly reduced during exercise [11], probably due to passive recruitment and distension of a compliant pulmonary circulation and/or an active flow-mediated vasodilatation. Our patients without $\mathrm{PH}$ showed the same PVR and TPR response pattern as the $\mathrm{PH}$ group, indicative of early and significant pre-capillary vascular changes also existing in this group. Furthermore, during exercise, the non- $\mathrm{PH}$ group had a considerably larger drop in compliance relative to the change in PVR compared with the PH group, which is consistent with the findings of SAOUTI et al. [28], who suggested that a small increase in PVR accompanied by a relatively larger drop in PAC to be a hallmark of early changes in the pulmonary vascular bed.

\section{Exercise decline in $\mathrm{PaO}_{2}$ and haemodynamics}

In the present study, only a minor exercise-induced decline in $\mathrm{PaO}_{2}$ was observed, which is in contrast to data presented by BOERRIGTER et al. [29], but is comparable with the observations by CHRISTENSEN et al. [30]. Augmented pressure responses during exercise partly occurred in our non- $\mathrm{PH}$ population in the presence of minor decline in $\mathrm{Pa}_{1} \mathrm{O}_{2}$ during exercise, and could indicate a mechanism other than hypoxaemia.

\section{Clinical implications}

GOLD classification is valuable in terms of differentiation of airway disease severity [2] but, in our study, showed a poor relationship with mean $P$ pa at rest (fig. 1). Its use as a predictor for $\mathrm{PH}$ is thus restricted. Furthermore, the results demonstrated that patients classified as GOLD III had mean $P$ pa distribution from low normal (mean $P$ pa $10 \mathrm{mmHg}$ ) to severe PH (mean $P$ pa $38 \mathrm{mmHg}$ ). A similar pattern was shown for GOLD stages II and IV, and half of the patients in GOLD stage IV did not have $\mathrm{PH}$ according to current guidelines (fig. 1).

The present study has also demonstrated that higher resting mean $P$ pa is associated with impaired functional capacity (6MWD) independent of demographics, Ppcw and GOLD classification. To our knowledge, this study is the first to report reduced functional capacity related to higher resting mean $P$ pa in an outpatient population. Similar findings have been reported in severe COPD patients listed for lung transplantation [31]. Interestingly, 6MWD, in our cohort decreased gradually by increasing PVR at peak exercise, even when controlling for confounding variables. A strong correlation between exercise afterload variables, PVR and PAC, and maximum workload was observed, and could further endorse the clinical relevance of exercise-induced PH. Patients with exercise-induced $\mathrm{PH}$ are particularly prone to developing persistent $\mathrm{PH}$ in the long term, as exercise mean $P$ pa $>30 \mathrm{mmHg}$ is a marker of disease progression [32]. Thus, the present non-PH group, and especially those with $\Delta$ mean $P$ pa/ $\Delta \mathrm{CO}>3 \mathrm{mmHg} \cdot \mathrm{L}^{-1} \cdot \mathrm{min}$, should be followed up longitudinally to see if they develop $\mathrm{PH}$.

\section{Study limitations}

The local ethical committee in Norway does not approve invasive RHCs on healthy controls and, therefore, the present study did not provide haemodynamic data for a healthy ageand sex-matched control group. However, comparable data on haemodynamic exercise responses in historical controls have been published, albeit with a limited numbers of articles in the population aged $>50$ years.

$14 \%$ of the patients showed exercise $P$ pcw $>20 \mathrm{mmHg}$, and hence a post-capillary contribution to elevated mean $P$ pa during exercise cannot be entirely excluded. An upper limit for $P$ pcw was not adopted due to the paucity of data supporting the previously used cut-off point of $20 \mathrm{mmHg}$ in a population aged $>50$ years. $\mathrm{CO}$ was measured by the thermodilution technique only once at maximal exercise at highest $f c$. Rapid decline in both $P$ pa and $f C$ were observed when exercise was discontinued, and several $\mathrm{CO}$ measurements would thus have underestimated peak $\mathrm{CO}$.

CPET was performed separately $24 \mathrm{~h}$ prior to RHC, which reflects the standard in our laboratory. A concomitant performance of these two procedures would have been preferable. It is, however, reasonable to assume that clinical and haemodynamic 
conditions did not differ in this short period of time, and the exercise levels were similar during CPET and RHC.

Upright positioning during exercise most closely mimics normal physical activity. However, the RHC exercise test in this study was performed in the supine position due to more stable and reliable pressure curves in this position. Despite the postural impact on haemodynamic variables, the relative changes between rest and exercise haemodynamics are most likely to be comparable.

It has been postulated that dynamic lung hyperinflation in COPD may contribute to the development of exercise-induced $\mathrm{PH}$. At the time of inclusion, measurements of inspiratory capacity were not routinely performed in our exercise laboratory and, therefore, it is difficult to conclude with certainty that the exaggerated response of $\Delta$ mean $P$ pa $/ \Delta C O$ and PVR in COPD compared with historical controls is due solely to a vasculopathy.

Our patients represent a well-selected group of patients from an outpatient population. The main purpose was to study exclusively pre-capillary prevalence of $\mathrm{PH}$ and pre-capillary haemodynamic responses to exercise. Therefore, our findings are not necessarily applicable to all COPD patients.

\section{Conclusions}

The present study showed a prevalence of PH of 5\%, 27\% and $53 \%$ in a cohort of COPD outpatients in GOLD stage II, III and $\mathrm{IV}$, respectively. Exercise revealed abnormal haemodynamic responses in the $\mathrm{PH}$ group. However, similar and comparable haemodynamic response patterns were also observed in a large section of the non-PH group. Resting haemodynamics, however, were inadequate to identify early pulmonary vascular disease. The future definition of $\mathrm{PH}$ on exercise should rely on the slope of mean $P$ pa, related to $\mathrm{CO}$ or workload, rather than the absolute values of mean $P$ pa, to account for the large interindividual variability in physical performance in COPD patients.

\section{SUPPORT STATEMENT}

Funding was supplied by Eastern Norway Regional Health Authority and Dept of Cardiology, Oslo University Hospital, Aker, Norway (grant number 2007006).

\section{STATEMENT OF INTEREST}

None declared.

\section{REFERENCES}

1 Cooper R, Ghali J, Simmons BE, et al. Elevated pulmonary artery pressure. An independent predictor of mortality. Chest 1991; 99: 112-120.

2 Rabe KF, Hurd S, Anzueto A, et al. Global strategy for the diagnosis, management, and prevention of chronic obstructive pulmonary disease: GOLD executive summary. Am J Respir Crit Care Med 2007; 176: 532-555.

3 Sanz J, Kariisa M, Dellegrottaglie S, et al. Evaluation of pulmonary artery stiffness in pulmonary hypertension with cardiac magnetic resonance. JACC Cardiovasc Imaging 2009; 2: 286-295.

4 Miller MR, Hankinson J, Brusasco V, et al. Standardisation of spirometry. Eur Respir J 2005; 26: 319-338.
5 Gulsvik A, Tosteson T, Bakke P, et al. Expiratory and inspiratory forced vital capacity and one-second forced volume in asymptomatic never-smokers in Norway. Clin Physiol 2001; 21: 648-660.

6 Wanger J, Clausen JL, Coates A, et al. Standardisation of the measurement of lung volumes. Eur Respir J 2005; 26: 511-522.

7 Lewis GD, Murphy RM, Shah RV, et al. Pulmonary vascular response patterns during exercise in left ventricular systolic dysfunction predict exercise capacity and outcomes. Circ Heart Fail 2011; 4: 276-285.

8 Hansen JE, Sue DY, Wasserman K. Predicted values for clinical exercise testing. Am Rev Respir Dis 1984; 129: S49-S55.

9 Wasserman K, Whipp BJ. Excercise physiology in health and disease. Am Rev Respir Dis 1975; 112: 219-249.

10 Galiè N, Hoeper MM, Humbert M, et al. Guidelines for the diagnosis and treatment of pulmonary hypertension. Eur Heart $J$ 2009; 30: 2493-2537.

11 Kovacs G, Olschewski A, Berghold A, et al. Pulmonary vascular resistances during exercise in normal subjects: a systematic review. Eur Respir J 2012; 39: 319-328.

12 Degre S, De Coster A, Messin R, et al. Normal pulmonary pressure-flow relationship during exercise in the sitting position. Int Z Angew Physiol 1972; 31: 53-59.

13 Kovacs G, Berghold A, Scheidl S, et al. Pulmonary arterial pressure during rest and exercise in healthy subjects: a systematic review. Eur Respir J 2009; 34: 888-894.

14 Lewis GD. Pulmonary vascular response patterns to excercise: is there a role for pulmonary arterial pressure assessment during excercise in the post-dana era? Adv Pulm Hypertens 2010; 9: 92-100.

15 Chatila WM, Thomashow BM, Minai OA, et al. Comorbidities in chronic obstructive pulmonary disease. Proc Am Thorac Soc 2008; 5: 549-555.

16 Falk JA, Kadiev S, Criner GJ, et al. Cardiac disease in chronic obstructive pulmonary disease. Proc Am Thorac Soc 2008; 5: 543-548.

17 Chaouat A, Naeije R, Weitzenblum E. Pulmonary hypertension in COPD. Eur Respir J 2008; 32: 1371-1385.

18 Naeije R. Pulmonary hypertension and right heart failure in chronic obstructive pulmonary disease. Proc Am Thorac Soc 2005; 2: 20-22.

19 Scharf SM, Iqbal M, Keller C, et al. Hemodynamic characterization of patients with severe emphysema. Am J Respir Crit Care Med 2002; 166: 314-322.

20 Minai OA, Chaouat A, Adnot S. Pulmonary hypertension in COPD: epidemiology, significance, and management: pulmonary vascular disease: the global perspective. Chest 2010; 137: 39S-51S.

21 Kessler R, Faller M, Fourgaut G, et al. Predictive factors of hospitalization for acute exacerbation in a series of 64 patients with chronic obstructive pulmonary disease. Am J Respir Crit Care Med 1999; 159: 158-164.

22 Saggar R, Lewis GD, Systrom DM, et al. Pulmonary vascular responses to exercise: a haemodynamic observation. Eur Respir J 2012; 39: 231-234.

23 Granath A, Jonsson B, Strandell T. Circulation in healthy old men, studied by right heart catheterization at rest and during exercise in supine and sitting position. Acta Med Scand 1964; 176: 425-446.

24 Kubo K, Ge RL, Koizumi T, et al. Pulmonary artery remodeling modifies pulmonary hypertension during exercise in severe emphysema. Respir Physiol 2000; 120: 71-79.

25 Wagner PD, Gale GE, Moon RE, et al. Pulmonary gas exchange in humans exercising at sea level and simulated altitude. J Appl Physiol 1986; 61: 260-270.

26 Reeves JT, Moon RE, Grover RF, et al. Increased wedge pressure facilitates decreased lung vascular resistance during upright exercise. Chest 1988; 93: 97S-99S.

27 Reeves JT, Groves BM, Sutton JR, et al. Operation Everest II: preservation of cardiac function at extreme altitude. J Appl Physiol 1987; 63: 531-539.

28 Saouti N, Westerhof N, Postmus PE, et al. The arterial load in pulmonary hypertension. Eur Respir Rev 2010; 19: 197-203. 
29 Boerrigter BG, Bogaard HJ, Trip P, et al. Ventilatory and cardiocirculatory exercise profiles in COPD: the role of pulmonary hypertension. Chest 2012; 142: 1166-1174.

30 Christensen CC, Ryg MS, Edvardsen A, et al. Relationship between exercise desaturation and pulmonary haemodynamics in COPD patients. Eur Respir J 2004; 24: 580-586.
31 Sims MW, Margolis DJ, Localio AR, et al. Impact of pulmonary artery pressure on exercise function in severe COPD. Chest 2009; 136: 412-419.

32 Kessler R, Faller M, Weitzenblum E, et al. "Natural history" of pulmonary hypertension in a series of 131 patients with chronic obstructive lung disease. Am J Respir Crit Care Med 2001; 164: 219-224. 